\title{
Integrated Engineering - A SME-Suitable Model for Business and Information Systems Engineering (BISE) towards the Smart Factory
}

\author{
Günther Würtz and Bernhard Kölmel \\ Steinbeis University Berlin, Gürtelstraße 29A/30, 10247 Berlin \\ Steinbeis-Stiftung für Wirtschaftsförderung, Willi-Bleicher-Str. 19, 70174 Stuttgart, Germany
}

\begin{abstract}
Integrated Engineering is a BISE-model and combines the following dimensions within an network-oriented SME:

- Cooperation engineering: networking of product features, process features and project parameters (internal Relationship Management);

- Collaborative networking: initiation, management, controlling of business relationships along the value chain (external RM);

- Corporate range: adaptation of the xRM-principles to the product development process (project engineering), to the complexity management (variants engineering) and to the life cycle engineering.
\end{abstract}

Integrated Engineering consists of 3 modules:

- myPEP_cube: customized integration of product features, process features and engineering rules based on the specific product development process (PEP);

- myVariants_cube: customized integration of the value-added system, the variants life cycle and the variants design rules based on the complexity management system;

- myxRM_cube: customized integration of the corporate know-how, the collective competence and the collaborative guide lines based on the product- and technology life cycle process within the production network.

\section{Introduction: Increasing Complexity - Requirements for SMEs}

There is a growing trend in manufacturing to move towards highly customized products, ultimately one-of-a-kind, which is reflected in the term mass customization. Important challenges in such manufacturing contexts can be elicited from the requirements of complex technical infrastructures, like security infrastructures, alternative energy, or illumination systems in large public buildings or urban equipments, but also in more traditional complex products such as customized kitchens:

- These products typically require a variety of competencies and resources, hardly available in a single enterprise, which calls for collaboration among several companies and individuals. 
- A complex multi-supplier product with a high degree of customization would benefit from associated services (e.g. maintenance support, assistance wizard, etc.), which are more difficult to plan and arrange as with standardized mass products.

- Customization demands that the recipients of the customized goods transfer their specific needs and desires into a concrete product specification. This calls for customers' integration into value creation to detailed defining, configuring, matching, and/or modifying an individual solution.

These requirements cannot be fulfilled by centrally managed organisations or systems any more - a new approach for organisations and enterprises is necessary. [1]

\section{Cyber Physical Systems: The Smart Factory}

Cyber-physical systems (CPS) are engineered systems that are built from and depend upon the synergy of computational and physical components. Examples can be found in smart electric grid, smart transportation, smart buildings, smart medical technologies, next-generation air traffic management, and advanced manufacturing. Recent efforts were focused on connecting objects (devices, sensors, sub-systems) to Internet, which led to the term Internet of Things; the challenge is now how to organize "communities" or "societies" ("ecosystems") of cyber-physical artifacts where flat organizational structures are not appropriate [2].

CPS may be equipped with intelligent sensors and actors which allow them to interact with the environment. This enables CPS on the one hand to adopt its behaviour to the environment and on the other hand to learn new ways of reaction and even the strategy to optimize this. These "smart" abilities belong to machines but also to products and modules - even in the phase of early development. This means that these smart products can control the whole production system in an early phase of development and can interact between machine and user [3].

\section{Important Requirements for Smart Factories}

Concerning the presented BISE model mainly developed for advanced manufacturing companies, the main requirements are:

Smart Products: standardization of mechatronical interfaces (mechanical, electronical, software-architectural) in order to realize the interoperability between different enterprise systems using and following design rules for standardized product development.

Smart Processes: design of innovative process chains capable to react and control the interdependencies within the processes inside the factory and even outside the factory within the value chain or the collaborative network.

Smart IT-Systems: integration of heterogeneous IT-Systems by realizing a consistent (business/software as a) service-model taking into account different 
systems as e.g. Product Lifecycle Management (PLM), Enterprise Ressource Planning (ERP), Management Execution System (MES), etc.

As a conclusion: in order to make the Smart Factory approach happen, an integrated (engineering) approach of product-process-organization level is needed [3]

\section{Current Achievements and Goals towards the Smart Factory}

CPS in advanced manufacturing and producing companies mainly tackle with the two key processes order fulfillment and product(ion) development. To improve these 2 key processes, more and more the system of the new product development process is going to be installed, combining well known aspects of simultaneous engineering, concurrent engineering and value stream designing. But to achieve the goals of the smart factory, there still the following main issues concerning these 2 main processes have to be solved [4], [5]:

- Interoperability between the production units of different suppliers

- Adaptivity of product features and processes of the whole value chain

- Integrated engineering of mechanical, electronical and software functions.

Conclusion: current gaps towards the smart factory.

CPS in producing companies therefore require on the one hand the aspects of collaboration engineering and on the other hand a cooperative networking approach, based on a life cycle engineering system to ensure the future development of the company (corporate range).

\section{$5 \quad$ Our Approach for Smart Factories: Model of Integrated Engineering}

The Business and Information System Engineering model of "Integrated Engineering" combines the following three dimensions within an innovative SME:

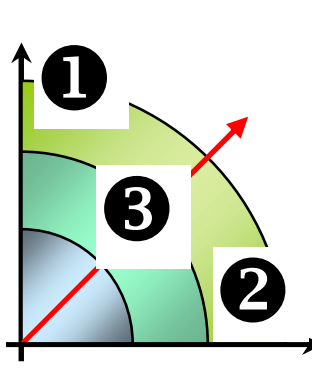

1. Collaboration engineering: the networking of product features, process features and project parameters in order to achieve product and process excellence;

2. Cooperative networking: the initiation, management and controlling of business relationships along the value chain in order to achieve business excellence;

3. Corporate range: the value-integrated integration of product development process (myPEP), complexity management system (myVariants) and the life cycle (myxRM) engineering.

The business model hereby is based on

1. The concept of integrated engineering which attempts to transfer the subject oriented product development process (mechanical, electronical, software) 
towards a systems integrated approach (concerning collaboration engineering approach) [6].

2. The concept of anything Relationship Management (xRM) which attempts to design and optimize the growing complexity of relationship structures towards the smart factory (concerning cooperative networking approach) [7].

\section{Our Solution for Collaborative Networks}

The business model Integrated Engineering consists of 3 modules to be developed as a customized solution for each SME, identifying the relevant parameters for each module:

1. myPEP_cube: the customized integration of product features, process features and engineering rules based on the specific product development process (PEP)

2. myVariants_cube: the customized integration of the value-added system, the variants life cycle and the variants design rules based on the complexity management system

3. myxRM_cube: the customized integration of the corporate know-how, the collective competence and the collaborative guide lines based on the product- and technology life cycle process within the production network

\section{Use Case 1: myPEP@Feinmetall}

Feinmetall is a SME in the testing area and has plenty of experience in safely bonding electronic components in the test room. The number of test card and test adapter projects and their level of complexity rose so sharply over the last few years at Feinmetall, that something had to be done to take control of the situation again. The next step:introduce a standardized process for completing engineering projects. This process needed to do three things: help staff meet stipulated project completion deadlines, reduce the number of rounds of changes and in doing so, improve productivity among the project team. For years, Feinmetall has used a project management system that organizes the scope of projects as well as timings. So the mandate for the project was clear. From now on, engineering projects needed to follow one standardized process - from the first stage of development to the production handover - and include defined work packages to help staff accurately assess costs and necessary resources.

Joining forces with the Steinbeis experts, the Feinmetall team embarked on the project using an engineering method called myPEP. This links

- $\quad$ product engineering with

- process engineering and

- $\quad$ project engineering (rules),

uniting the seasoned approaches of simultaneous engineering with project management to create an integrated project engineering system. Designed around each company individually, myPEP integrates and synchronizes three core components: 
- $\quad$ work packages that outline the PEP;

- working guidelines (consisting of checklists and design rules) that govern how products and production must be designed;

- a kit of ready-to-use tools for fully functional products and processes within budget.

Work packages needed to create two things: product development based on established routines and carefully coordinated production procedures. One important resource in this phase was a classification covering three types of projects: standard; application/change; one-of-a-kind. One-of-a-kind-projects are the only ones that require engineers to work through the work packages according to plan. For application/change and standard projects, engineers agreed to use a streamlined, shortened version to make the best use of limited resources and man-hours.

Spanning checklists and design guidelines, the set of rules outlines standards drawn from best practice. The biggest task lay in clearing up. Nearly half of the 50 applicable procedures and checklists were eliminated entirely; those that remained were revised, shortened and tailored to each particular application.

The greatest gains in efficiency were made when the teams structured the methods. Over the years, employees at Feinmetall had amassed an arsenal of product development and process planning methods. Here again, a cleanup was the order of the day. The methods that were kept in place were trimmed down to an easy-to-use "light version" and assigned to individual work packages. When it came to what is known at Feinmetall as a "specialist project", the decision maker stook a much different tack.

The outcome: a standardized product engineering process myPEP@Feinmetall that primarily allows Feinmetall to offer a greater sense of security to all of the project stakeholders. This means that senior managers can manage the right projects with the right priority, thus minimizing risk. Heads of specialist departments will also have fewer fires to put out as they will be able to take other departmental needs into account earlier. Project managers will spend less time checking up on things internally. And project team members will see their productivity rise - now that they know precisely what needs to be delivered, by when, and what that will require. This tailormade PEP affords everyone involved in the project more time to come up with solutions to the real technical and business challenges they are faced with. The supposed drain on creativity has been transformed into a catalyst for creativity!

myPEP@Feinmetall now builds the basis for work within the network of customers and suppliers of Feinmetall. [8]

\section{Use case 2: myVariants@ZF}

ZF Lemförder, a member of the ZF Friedrichshafen AG group of companies, makes products such as tie rods, steering rods, suspension components and suspension modules. The concept for the solution of myVariants being used in this specific use case is based on a meta-modell, consisting of principles of method engineering and built of

- $\quad$ a 3 step model of phases which are organized within a process model;

- a set of techniques and tools (design rules) within each phase with defined input and output data which are directly linked together; 
- a framework of objects and tools for product, process and project description (value-added system) combining all necessary information to create a variant systems.

The 3 step model: phases to install a customized variant system: the variants life cycle

- Step 1 - clearing the decks: stripping down products by removing overlaps, items gathering dust and profit killers

- Step 2 - design: designing products by laying down standard products and "specials" based on standard templates

- Step 3 - taking control: sustainable implementation and adherence to defined product structures by adapting standard processes in sales, D\&D, logistics and production

In recent years, the number of different steering tie rods, axle rods and ball joints has risen sharply. The aim was therefore threefold: to slash the time needed for D\&D to issue a detailed offer; to reduce prototype delivery times once quote were given the go-ahead; and to shorten delivery lead times for serial products. All of this should be achieved by standardizing products and processes, as part of on-going plant development projects. Even as the project got underway, ZF knew it would be necessary to address many issues. All processes are integrated, so sales is involved through actively selling product standards, production is involved with standardized manufacturing processes, and financial accounts are involved with fixed calculation models for standardized products. The scope of the project was therefore clear: a new end-toend variant management system was needed, involving standard processes that make it possible to shorten lead-times by more than $50 \%$ - from the first point of contact with the customer to final delivery - without reducing the deliverable scope of products or raising prices. The aim was to map customer solutions by using components and assemblies made from defined (standard) "building blocks." To define standard products, consensus was needed with all departments as to which standards should be used.

Toolset for product and process design rules and the framework (value-added system)

An important tool in this respect was the use of a software program for product configuration. This made it possible to significantly reduce the time taken to submit offers, draft designs and prepare work processes. Equally important was the task of dividing the entire job handling process into standard product processes and special product processes. A major help in this respect turned out to be a lean production system (LPS) which had already been in place at ZF for a number of years. Because of the underlying principles it is based on, an LPS makes it possible to make variants quite late in the production process. This makes it easier to reconcile the goals of maximizing capacity use while keeping batch sizes and variants flexible. Extending LPS principles to the entire job handling process - based on similar methods - made a significant contribution to achieving overall goals. Instruction covered the theory underlying the new system as well as knowledge-sharing by learning "on the job" as part of live project work. 
In the three areas looked at - ball joints, axle rods and steering/tie rods - laying down standards based on pre-defined building blocks resulted in different levels of standardization. In some areas, this was as high as $65 \%$. In combination with process optimizations, the resulting throughput times were reduced down to $50 \%$, which was even better than planned. But for the top management, the change in attitude among co-workers was more important than bare numbers. [9]

\section{Use case 3: myxRM@2E}

$2 E$ mechatronic, is a specialist in the development of innovative mechatronics products in the fields of sensors, precision injection molding and microelectromechanical systems. The project scope was clearly defined: the second generation of the inclination sensor should be based on a clear design principle - similar to the architecture of a house. Preplanned, combinable product and process elements should be used to generate new customer-specific solutions quickly and reliably. The entire life cycle of the product, from initial brainstorming to follow-on products, should be taken into account, and all engineering processes should be set up accordingly. For functions and processes beyond 2E's core competences, value creation partners should be identified and successfully integrated into company networks.

The team used the Steinbeis Transfer Center's three-phase model:

1. Phase 1: Customer requirements and system development: Systematically classify customer and market needs and develop suitable integrated technology and functional modules.

2. Phase 2: Product classification/configuration: Draw up a product catalog of basic functionalities, standard (catalog) options and customer versions.

3. Phase 3: Process evaluation and value creation partners: Optimize core processes (internal) for core functions; evaluate special processes (external) for special functions, network processes efficiently, adapt regularly.

Especially in phase 3, the principle of XRM was used in order to organize and control the relevant process relations within the collaborative network $2 \mathrm{E}$ being member of. $\mathrm{xRM}$ describes a management concept in which all levels of relationships are coordinated and transparent, interactive processes are created. The implementation is based on platforms and modular, domain specific applications building upon these platforms.There are two application areas: internal organizational RM uses xRM platforms e.g. for documentation within the organization; organization-wide RM supports the management and controlling of business relationships.

Step 3.1: self-assessment (corporate wiki):_highlighted where the core competences of $2 \mathrm{E}$ lie within the engineering processes. However, certain key figures highlighted that there was still plenty of potential to standardize and optimize the inclination sensor product architecture. To avoid adapting products to each new customer, the team systematically analyzed selected target groups in the chosen markets, and implemented their requirements in appropriate product modules. This massively reduces the time-to-market for each order - and the freed-up development capacity can now be used for customer projects that really do match company goals. For the catalog modules, the team determined and optimized corresponding engineering processes. 
Step 3.2: network-assessment (collective competence): 2E no longer develops special processes for tailored solutions, but buys them from reliable network partners. This requires on the one hand the identification of all required competences within the whole life-cycle-process and on the other hand an evaluation scheme to assess potential network partners due to these requirements. The matching of requirements and competences can be supported by suitable software services.

Step 3.3: process integration (collaborative know-how): $2 \mathrm{E}$ is designing an entire product portfolio for each application area - after all, they have the technological expertise to do this. But it takes careful planning to integrate this sensibly into the existing business fields (automotive industry, medical industry, process industry) without customer projects getting in each other's way. This has to be done by taking into consideration the whole process landscape of all network partners in order to reach a maximum of synergy between the different processes inside the company (each business field) and outside the company (each network partner). This will result in a maximum of efficiency and therefore profit. [10]

\section{Conclusions}

The business model Integrated Engineering helps to create the customized company system "my_smartfactory" and therefore enables the company to contribute successfully within its collaborative network, being capable to adapt on the one hand to changing customers requirements and on the other hand to changing business and process relations within the collaborative network.

The presented "customized cube solutions" are all based on a common structure including the relations between the different aspects of the cubes and can therefore be used as a basic tooling to create the company-specific, customized solution for successful collaborative and cooperative networking "my_smartfactory". Nevertheless, the identification of the specific parameters of each company which form the basis for the creation of the customized solutions have to be developed for any use case separately. This effort should be reduced by using basic business scenarios which is one of the main aspects of the EC-funded research project GloNet [1]. Within the EU research project GloNet (Glocal enterprise network focusing on customer-centric collaboration), the $\mathrm{xRM}$ plus the Integrated Engineering approach is applied in real life settings. GloNet aims at designing, developing, and deploying an agile virtual enterprise environment for networks of SMEs involved in highly customized and service-enhanced products through end-to-end collaboration with customers and local suppliers (co-creation).

Main issues to be developed for the Integrated Engineering@xRM approach are:

- Creation of a framework and of business scenarios in order to identify the "global space" for companies acting in collaborative networks;

- Identification of key performance indicators in order to create the scenario for defining the my_IntegratedEngineering@smartfactory solution;

- Development of guidelines for mainly SMEs how to build up or improve their collaborative network for the whole life cycle of their products. 
Acknowledgements. The authors would like to thank the European Commission for the financial support of the R\&D project GloNet within the FinES cluster.

\section{References}

[1] Camarinha-Matos, L.M., Afsarmanesh, H., Koelmel, B.: Collaborative Networks in Support of Service-Enhanced Products. In: Camarinha-Matos, L.M., Pereira-Klen, A., Afsarmanesh, H. (eds.) PRO-VE 2011. IFIP AICT, vol. 362, pp. 95-104. Springer, Heidelberg (2011)

[2] Camarinha-Matos, L.M., Afsarmanesh, A.: Taxonomy of Collaborative Network Forms; GloNet project, Draft Working Document; FinES - Task Force on Collaborative Networks (2012)

[3] Broy, M. (Hrsg.): Cyber Physical Systems -Innovation durch SW-intensive eingebettete Systeme (acatech diskutiert). Springer, Heidelberg (2010)

[4] Broy, M. (Hrsg.): Cyber Physical Systems -Integrierte Forschungsagenda (acatech Studie). Springer, Heidelberg (2012)

[5] Passiante, G.: Evolving towards the Internetworked Enterprise. Springer Science and Business Media (2010)

[6] Anderl, R. (Hrsg.): Smart Engineering - Interdisziplinäre Produktentstehung (acatech Diskussion). Springer, Heidelberg (2012)

[7] Britsch, J., Kölmel, B.: Anything Relationship Management as Basis for Global Process Management in Networked Enterprises. In: 6th International Conference on the Proceedings of I-ESA 2012, Valencia (2012)

[8] Würtz, G.: The art of getting everthing done - seeing engineering projects through to completion. Transfer - The Steinbeis Magazine, 20-21 (2011)

[9] Würtz, G.: Combining customer-orientation with standardization. Transfer - The Steinbeis Magazine, 25-26 (2011)

[10] Würtz, G.: Life Cycle Engineering - Thinking about tomorrow- today. Transfer - The Steinbeis Magazine, 29-30 (2011) 